\title{
Cost Analysis in Helicobacter pylori Eradication Therapy Based on a Database of Health Insurance Claims in Japan
}

This article was published in the following Dove Press journal: ClinicoEconomics and Outcomes Research

\author{
Kengo Tokunaga $\mathbb{D}^{\prime}$ \\ Chihiro Suzuki $\mathbb{D}^{2}$ \\ Miyuki Hasegawa $\mathbb{D}^{2}$ \\ Ikuo Fujimori $\mathbb{D}^{2}$ \\ 'Department of General Medicine, \\ Kyorin University School of Medicine, \\ Tokyo, Japan; ${ }^{2}$ Japan Medical Office, \\ Takeda Pharmaceutical Company Limited, \\ Tokyo, Japan
}

Objective: Cost-benefit is an important consideration for Helicobacter pylori (H. pylori) eradication in Japan, where 1.5 million patients were reported to receive first-line eradication annually. This study aimed to identify the optimal cost-saving triple therapy regimen for H. pylori eradication in Japan.

Materials and Methods: This retrospective observational study used data from a largescale, nationwide health insurance claims database (2015-2018). Using success rates of firstline eradication, mean total costs of first-line and second-line eradications per patient were compared between regimens including a potassium-competitive acid blocker (P-CAB) or a proton pump inhibitor (PPI), and between two clarithromycin (CAM) doses (400 and $800 \mathrm{mg} /$ day). Subgroup analyses by smoking habit or body mass index (BMI) were performed.

Results: Among propensity score (age, gender, CAM dose, disease name)-matched patients (P-CAB regimen, $n=22,002$; PPI regimen, $n=22,002$ ), total costs were lower with the P-CAB than the PPI regimen (Japanese yen [JPY] 12,952 vs 13,146) owing to significantly higher first-line eradication rates with the $\mathrm{P}-\mathrm{CAB}$ regimen $(93.6 \%$ vs $79.7 \% ; p<0.001)$. For both regimens, even among current smokers or patients with BMI $\geq 25 \mathrm{~kg} / \mathrm{m}^{2}$, eradication rates did not differ by CAM dose, and total costs were approximately JPY1000 lower with CAM $400 \mathrm{mg}$ /day than with CAM $800 \mathrm{mg} /$ day.

Conclusion: High success rate of first-line eradication contributes to saving in total eradication costs by reducing costs of subsequent therapy, irrespective of patients' smoking status or BMI class. The combination of more potent acid-inhibitory medicine and low-dose CAM may be the optimal regimen in terms of efficacy and cost-benefit in Japan.

Keywords: Japanese claims database, cost analysis, potassium-competitive acid blocker, Helicobacter pylori eradication, clarithromycin-dose, health resource

\section{Introduction}

In 2015, approximately 4.4 billion people were estimated to be infected with Helicobacter pylori (H. pylori) worldwide, and over half of the general population of East Asia was reported to be $H$. pylori positive. ${ }^{1} H$. pylori infection is a wellestablished cause of histological gastritis ${ }^{2}$ and is a risk factor for peptic ulcer, gastric mucosa-associated lymphoid tissue (MALT) lymphoma and idiopathic thrombocytopenic purpura following gastritis. ${ }^{2,3}$ Furthermore, H. pylori infection is thought to be a strong risk factor for gastric cancer. ${ }^{4,5}$ In 2008 , it was demonstrated that $H$. pylori eradication reduced the incidence of metachronous gastric
Correspondence: Kengo Tokunaga Department of General Medicine, Kyorin University School of Medicine, 6-20-2 Shinkawa, Mitaka-Shi, Tokyo, I8I-86II, Japan

Tel +8I-422-47-55I I

Email kentoku@ks.kyorin-u.ac.jp 
cancer after endoscopic resection of early gastric cancer. ${ }^{6}$ In February 2013, Japan became the first country in the world to support eradication therapy for $H$. pylori infection-associated gastritis through its national health insurance system. ${ }^{7}$ Gastric cancer consistently ranks among the top five cancers by incidence and mortality in Japan. ${ }^{8}$ Therefore, H. pylori eradication therapy is widely encouraged for primary prevention of gastric cancer. ${ }^{4}$

Various antibiotics (eg, clarithromycin [CAM], tetracyclines, metronidazole, bismuth) are used in $H$. pylori eradication treatment regimens around the world. $H$. pylor $i$ eradication rates, however, have decreased worldwide because of an increasing prevalence of antibiotic-resistant H. pylori. ${ }^{9}$ In Japan, the standard therapies for H. pylori eradication that are covered by health insurance are triple therapy administered for 7 consecutive days with an acidinhibitory medicine (proton pump inhibitor [PPI]), amoxicillin (AMPC), and CAM for first-line eradication, and replacement of CAM with metronidazole for second-line eradication. According to a surveillance of antimicrobial resistance in Japan, the prevalence of CAM-resistant H. pylori increased from $18.9 \%$ in 2002 to $40.3 \%$ in 2014. ${ }^{3,10}$ First-line eradication rates in Japan had decreased before 2015, concomitant with the increased prevalence of CAM-resistant $H$. pylori. ${ }^{11}$ In addition to PPIs, vonoprazan (VPZ), a novel potassium-competitive acid blocker (P-CAB), became available in Japan in February 2015. VPZ is stable in acidic environments, and exerts more potent and prolonged acid-inhibitory effects than PPIs. ${ }^{12}$ Several Japanese reports have shown that the P-CAB regimen has higher success rates of firstline eradication than the PPI regimens when treating CAM-resistant $H$. pylori strains. $^{13-15}$

In Japan, approximately 1.5 million patients were reported to have received $H$. pylori first-line eradication therapy annually since health insurance coverage was approved for $H$. pylori infection-associated gastritis in 2013 . $^{7}$ Thus, in addition to the efficacy and safety, costbenefit is becoming an increasingly important consideration when choosing a treatment option. Studies from Greece, Egypt and China have evaluated the costeffectiveness of $H$. pylori eradication treatment regimens using PPIs. ${ }^{16-18}$ In Japan, reports on the costs associated with eradication therapy are available for both PPI- and P-CAB-based regimens, but they are limited to singlecenter studies of short duration with small numbers of patients. ${ }^{19,20}$ Furthermore, data to identify a cost-saving regimen based on the eradication rate are currently lacking. The objective of this study, therefore, was to investigate the real-world cost of $H$. pylori eradication therapy to identify the optimal cost-saving combination of antibiotic dose and type of acid-inhibitory medicine for a triple therapy regimen by analyzing a large database from multi-center health insurance claims.

\section{Methods}

\section{Study Design and Data Source}

This was a retrospective, cross-sectional, observational study using large-scale administrative database derived from JMDC Inc. (https://www.jmdc.co.jp/, Tokyo, Japan) which contained data for a cumulative population of approximately 5.6 million individuals from 2005 to 2018. This secondary-use data are based on reimbursement claim by corporate health insurance belonging to employees and their families. These are strictly anonymized and unlinkable personal data for privacy protection, so that we have not submitted to ethical committees in accordance with the Ethical Guideline of Epidemiological Research in Japan. This includes standardized drug names, medical services, and disease names for claim coded by the International Classification of Diseases, 10th Revision (ICD-10). The dataset for this study included 185,824 patients who were prescribed omeprazole (OPZ), lansoprazole (LPZ), rabeprazole (RPZ), esomeprazole (EPZ), or VPZ with AMPC and CAM, or triple-drug blister packaged products containing acid-inhibitory medicines (LPZ, RPZ, or VPZ) for firstline eradication therapy with a diagnosis of $H$. pylori gastritis (ICD-10: K29.6) or H. pylori infection (ICD-10: A49.8) between January 2005 and June 2018 (Figure 1).

\section{Study Population}

Patients who were prescribed acid-inhibitory medicines (OPZ, LPZ, RPZ, EPZ, or VPZ) with AMPC and CAM, or packaged products for first-line eradication therapy for 7 consecutive days (Supplementary Tables S1 and S2) were included in the analysis. The following patients were excluded: (1) could not be tracked for 6 months before the prescription of medication for first-line eradication therapy (lookback period); (2) had not undergone a diagnostic test for $H$. pylori infection within 6 months after prescription of first-line eradication therapy (followup period); and (3) were not prescribed either CAM $400 \mathrm{mg} /$ day or $800 \mathrm{mg} /$ day. 


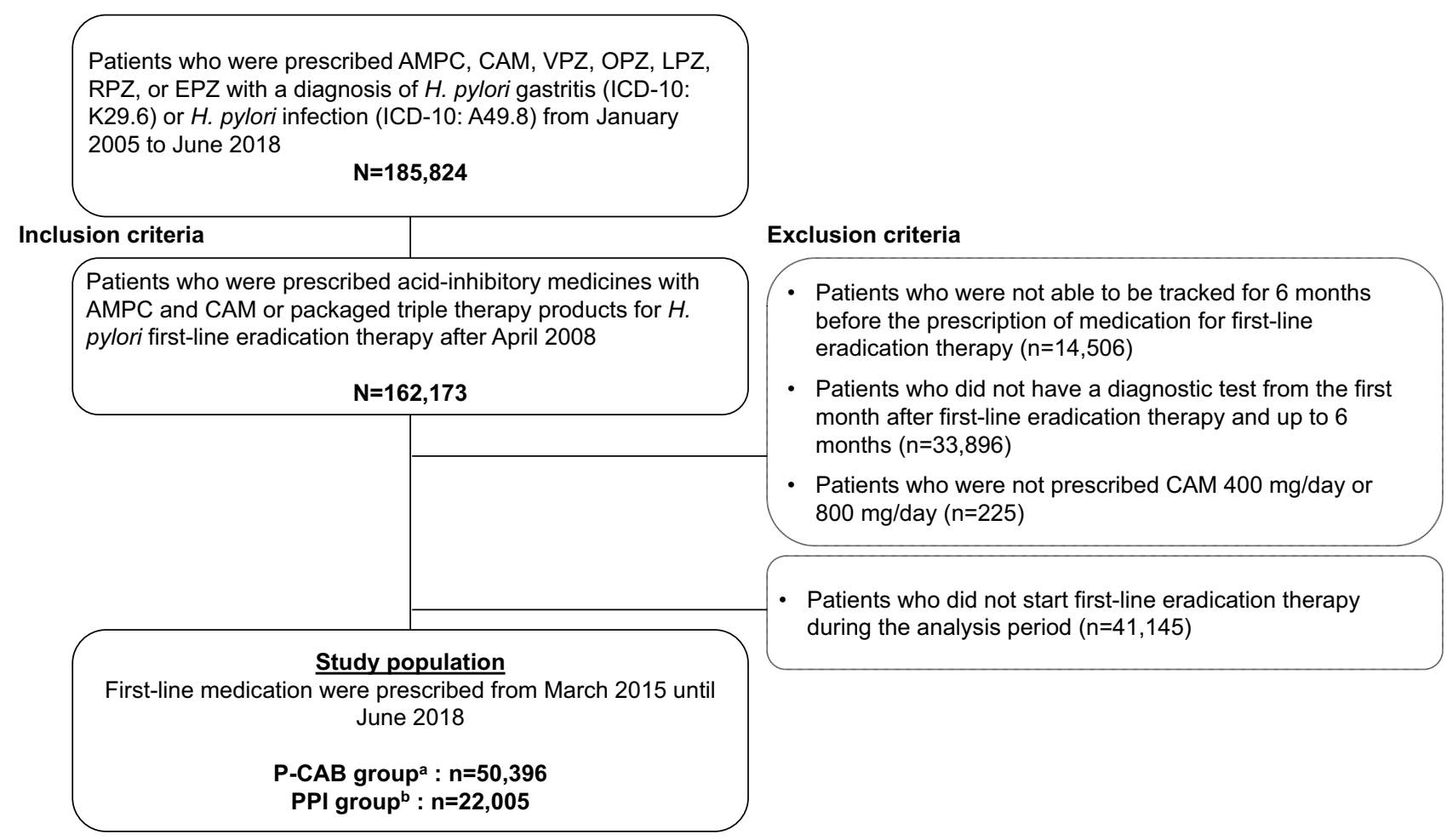

Figure I Selection of study population. This analysis included patients who were prescribed medication for $\mathrm{H}$. pylori first-line eradication therapy from March $20 \mathrm{I} 5$ to June 2018.

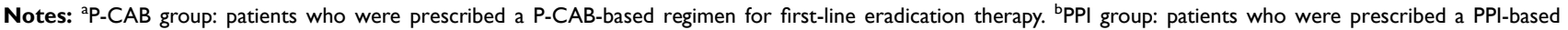
regimen for first-line eradication therapy.

Abbreviations: AMPC, amoxicillin; CAM, clarithromycin; EPZ, esomeprazole; ICD, International Classification of Diseases; LPZ, lansoprazole; OPZ, omeprazole; P-CAB, potassium-competitive acid blocker; PPI, proton pump inhibitor; RPZ, rabeprazole; VPZ, vonoprazan.

\section{Definition}

Successful first-line eradication therapy was defined as patients who completed any diagnostic tests (Supplementary Table S3) after prescription of medication for first-line eradication therapy and who had not been prescribed any medications for second-line eradication therapy (Supplementary Figure S1). ${ }^{21,22}$ The total cost per patient was estimated by build-up calculation of costs based on the successful first-line eradication rate, ie, the cost of second-line eradication therapy was added to the total costs among the patients who failed the firstline one according to the regimens. That cost comprised the direct cost of medication; diagnostic test; and subsequent visit fees (Supplementary Table S1). The cost of medication (per daily dose, including generic drug or off-label use) and diagnostic test (per a time) were derived from full value of claim data primary recorded for reimbursement claim. The subsequent visit fee was calculated using a reimbursement point to medical institution (JPY 720 per time) depending on the success (visits twice) or failure (visits three times because of necessary for additional visit of second diagnostic test) of firstline eradication therapy.

\section{Statistical Analysis}

The mean of total costs for eradication therapy per patient estimated by the first-line eradication rates was compared between the P-CAB and PPI regimens among patients who were prescribed any medications for first-line eradication therapy from March 2015 to June 2018. These dates were selected based on published reports that first-line eradication rates increased in 2015 because of the introduction of P-CAB in February 2015. ${ }^{21,23}$ To reduce the effect of potential confounding, propensity score matched pairs were used to account for any imbalance in the characteristics of the study population (age, gender, CAM dose, insurance names of disease) between the two regimens. The propensity score was predicted by a logistic regression analysis and a 1:1 matching was performed on the basis of nearest neighbor pair-matching within a caliper width of 0.25 , without replacement. Furthermore, among the three pairs of propensity score matched patients (age, gender and insurance names of disease), the first-line eradication rates and total costs were compared between the CAM $400 \mathrm{mg} /$ day and $800 \mathrm{mg} /$ day groups in the P-CAB and PPI regimens, respectively, and 
between the P-CAB + CAM $400 \mathrm{mg} /$ day and the PPI + CAM $400 \mathrm{mg} /$ day groups. These three propensity score matched populations were also stratified by patients' current smoking status (yes or no) and body mass index (BMI, overweight/obese $\geq 25 \mathrm{~kg} / \mathrm{m}^{2}$, normal weight: $<25 \mathrm{~kg} / \mathrm{m}^{2}$ ) according to the data from the annual health check-up closest to the date of first-line eradication therapy. The statistical significance for the first-line eradication rates was confirmed by performing a chi-square test. Missing or incomplete data were not imputed and a patient having any missing values was excluded from the analysis population. Data analysis was performed using SAS ${ }^{\circledR} 9.4$ (SAS Institute Inc., Cary, NC, USA).

\section{Results}

For the analysis between the P-CAB and the PPI regimens, the study population before propensity score matching comprised 72,401 patients ( $\mathrm{P}-\mathrm{CAB}$ regimen, $\mathrm{n}=50,396$; PPI regimen, $n=22,005$; Table 1). Mean ages and proportions of male were similar between the P-CAB and the PPI regimen (50.8 and 51.7 years old, and $58.3 \%$ and $57.4 \%$, respectively). However, proportions of indications (eg, 37.5\% and 30.6\% for gastritis) and high CAM dose $(29.3 \%$ and $35.4 \%)$ were difference between two regimens (Table 1). After the propensity score matching, the first-line eradication rate of the $\mathrm{P}-\mathrm{CAB}$ regimen was significantly higher than that of the PPI regimen $(93.6 \%$ vs $79.7 \% ; p<0.001$; Figure 2). The total costs of eradication therapy per patient for the P-CAB regimen (JPY 12,952 [USD 120]) were JPY 194 lower than for the PPI regimen (JPY 13,146 [USD 122]). The medication cost for first-line eradication therapy was JPY 1073 per patient higher in the $\mathrm{P}-\mathrm{CAB}$ regimen than in the PPI regimen. The diagnostic test costs for first-line eradication therapy were similar between the two regimens. The costs for second-line testing and medication in the P-CAB regimen (JPY 630) were approximately onethird of those in the PPI regimen (JPY 1828). Subsequent visit fees were slightly lower with a P-CAB regimen (JPY 1486) than with the PPI regimen (JPY 1586).

According to the subgroup analysis among the propensity score-matched patients between two CAM dose regimens (Supplementary Tables S4 and S5), the first-line eradication rates did not differ between the CAM $400 \mathrm{mg} /$ day and CAM

Table I Characteristics of Study Population in the P-CAB and PPI Regimens Before and After Propensity Score Matching

\begin{tabular}{|c|c|c|c|c|c|}
\hline & \multicolumn{2}{|c|}{ Unmatched } & \multicolumn{2}{|c|}{ Matched $^{\mathbf{a}}$} & \multirow{2}{*}{$\begin{array}{c}\text { Standardized Mean } \\
\text { Difference }\end{array}$} \\
\hline & $\begin{array}{c}\text { P-CAB } \\
(n=50,396)\end{array}$ & $\begin{array}{c}\text { PPI } \\
(n=22,005)\end{array}$ & $\begin{array}{c}\text { P-CAB } \\
(n=22,002)\end{array}$ & $\begin{array}{c}\text { PPI } \\
(n=22,002)\end{array}$ & \\
\hline Age (years), mean $\pm S D$ & $50.8 \pm 10.2$ & $51.7 \pm 10.1$ & $51.6 \pm 10.1$ & $51.7 \pm 10.1$ & -0.008 \\
\hline Male & $29,377(58.3)$ & $12,624(57.4)$ & I2,737 (57.9) & $12,622(57.4)$ & 0.011 \\
\hline High-dose CAM (800 mg/day) & $|4,77|(29.3)$ & $7,794(35.4)$ & $7824(35.6)$ & $7792(35.4)$ & 0.003 \\
\hline \multicolumn{6}{|l|}{ Insurance name of disease ${ }^{b}$} \\
\hline Gastritis $^{c}$ & $18,663(37.0)$ & $6,723(30.6)$ & $6,813(31.0)$ & $6,723(30.6)$ & 0.009 \\
\hline Peptic ulcer ${ }^{c}$ & $12,982(25.8)$ & $6,639(30.2)$ & $6,686(30.4)$ & $6,638(30.2)$ & 0.005 \\
\hline Gastric cancer $^{d}$ & $255(0.5)$ & $97(0.4)$ & $96(0.4)$ & $97(0.4)$ & -0.001 \\
\hline $\begin{array}{l}\text { Idiopathic thrombocytopenic } \\
\text { purpura }^{c}\end{array}$ & $50(0.1)$ & $38(0.2)$ & $30(0.1)$ & $35(0.2)$ & -0.006 \\
\hline Gastric MALT lymphoma $^{c}$ & $28(0.1)$ & $7(0.03)$ & $10(0.05)$ & $7(0.03)$ & 0.007 \\
\hline Gastroesophageal reflex disease & $10,389(20.6)$ & $4,803(21.8)$ & $4,747(21.6)$ & $4,802(21.8)$ & \\
\hline $\begin{array}{l}\text { Triple-drug blister packaged } \\
\text { products }\end{array}$ & $25,463(50.5)$ & $|6,77|(76.2)$ & $10,897(49.5)$ & $16,768(76.2)$ & \\
\hline Medical facilities with $<100$ beds & $32,074(63.7)$ & $14,168(64.8)$ & $13,906(63.2)$ & $14,168(64.8)$ & \\
\hline
\end{tabular}

Notes: All data are $\mathrm{n}(\%)$ unless otherwise noted. ${ }^{\mathrm{a}}$ The propensity score matching was used to account for imbalance in the characteristics of study population (age, gender,

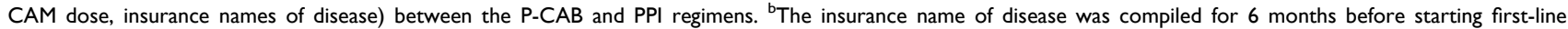
eradication therapy, including duplicates of insurance name for a patient. 'ICD-10 codes were K29.6 for gastritis, K25/K26 for peptic ulcer, D69.3 for idiopathic thrombocytopenic purpura, and C88.4 for gastric MALT lymphoma referred to in the ICD-I0 list (version 2013) at the Ministry of Health, Labour and Welfare (https:// www.mhlw.go.jp/toukei/sippei/index.html). ${ }^{\mathrm{d}}$ Codes for medical service fees for gastric cancer were K653, K655-2, K655-4, K655-5, and K657-2 referred to by the Medical Fee Information Service (http://www.iryohoken.go.jp/shinryohoshu/).

Abbreviations: CAM, clarithromycin; ICD, International Classification of Diseases; MALT, mucosa-associated lymphoid tissue; P-CAB, potassium-competitive acid blocker; PPI, proton pump inhibitor; SD, standard deviation. 


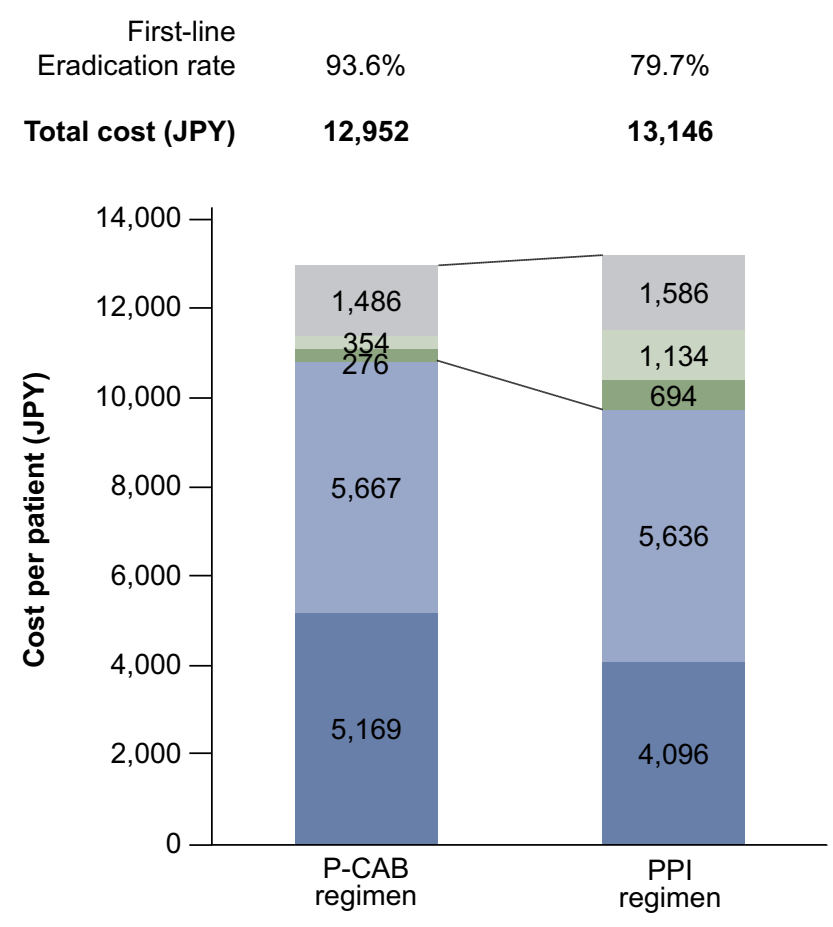

First-line medication

First diagnostic test

Second diagnostic test

Subsequent visit fee

Figure 2 Total costs for Helicobacter pylori eradication therapy between the P-CAB regimen and PPI regimens. Total costs are presented as mean values per patient. Abbreviations: JPY, Japanese yen; P-CAB, potassium-competitive acid blocker; PPI, proton pump inhibitor.

$800 \mathrm{mg}$ /day groups in both the P-CAB (93.8\% vs $93.5 \%)$ and PPI regimens (79.4\% vs $80.3 \%$; Figure 3 ). The total costs were JPY 993 lower and JPY 1139 lower with the $400 \mathrm{mg} /$ day (JPY 12,533 and JPY 12,704) than with the $800 \mathrm{mg} /$ day (JPY 13,526 and JPY 13,843) in the P-CAB and PPI regimens, respectively (Figure 3 ). In the $\mathrm{P}-\mathrm{CAB}$ regimen, among current smokers, the first-line eradication rates were similar between the CAM $400 \mathrm{mg} /$ day and $800 \mathrm{mg} /$ day groups (94.8\% vs 93.0\%; Figure 4), and the total costs were JPY 945 lower with P-CAB + CAM $400 \mathrm{mg}$ /day than with P-CAB + CAM 800 mg/day (JPY 13,004 vs JPY 13,949; Figure 4). Among overweight or obese patients in the P-CAB-treated group, the first-line eradication rates also did not differ between the CAM $400 \mathrm{mg} /$ day and $800 \mathrm{mg} /$ day groups (94.0\% vs $93.6 \%$ ), and the total costs were JPY 1037 lower with P-CAB + CAM $400 \mathrm{mg} /$ day than with CAM $800 \mathrm{mg}$ /day (JPY 12,537 vs JPY 13,574). Similar trends of eradication rates and total costs between CAM $400 \mathrm{mg}$ /day and $800 \mathrm{mg} /$ day groups were observed in the PPI-treated population overall, even among patients who currently smoke or are overweight/obese (Supplementary Figure S2). The comparison between the two regimens with CAM $400 \mathrm{mg} /$ day (Supplementary Table S6) showed that the total costs were JPY 184 lower with the P-CAB + CAM $400 \mathrm{mg} /$ day (JPY 12,578) than with the PPI + CAM $400 \mathrm{mg} /$ day regimen (JPY 12,762; Supplementary Figure S3) owing to the significant higher eradication rates in P-CAB-based regimen than in PPI-based regimen $(93.8 \%$ vs $79.4 \%$; $p<0.001$ ). Irrespective of patients' smoking or BMI class, similar trends of eradication rates and total costs were found between the P-CAB + CAM $400 \mathrm{mg} /$ day and the PPI + CAM $400 \mathrm{mg} /$ day groups, with the exception of the currently smoking subgroup, where the total cost was JPY 113 greater with P-CAB + CAM $400 \mathrm{mg} /$ day than with PPI + CAM $400 \mathrm{mg} /$ day (Supplementary Figure S4).

\section{Discussion}

In Japan, the prevalence of $H$. pylori infection has been falling gradually but remains high, with prevalence estimated at $27 \%$ in $2017 .{ }^{24-26}$ This high prevalence, combined with the scale of Japan's eradication program, which is responsible for an additional 13.6 million eradication cases over 16 years, ${ }^{26}$ underscore the importance of identifying cost-efficient ways of utilizing medical resources by the health insurance system. The use of a newlydeveloped drug would generally be expected to increase treatment costs, however, in case of $\mathrm{P}-\mathrm{CAB}$, we estimated that the high eradication rate could compensate for the high drug cost. Therefore, to determine if the high eradication success rate reduces the total costs of eradication therapy, we compared total costs and disaggregated costs between P-CAB and PPI regimens in the eradication therapy from 2015 to 2018.

The higher first-line eradication rates of the $\mathrm{P}-\mathrm{CAB}$ regimen compared with the PPI regimens in the current study were consistent with recent Japanese reports, not only from a clinical trial (VPZ regimen: $92.6 \%$ vs LPZ regimen: $75.9 \%{ }^{15}$ ), but also from real-world studies ${ }^{23,27}$ and an acute hospital database analysis (P-CAB regimen: $90.7 \%$ vs PPI regimen: $77.6-82.0 \%){ }^{21}$ As of 2020 , the medication cost is higher with a P-CAB than with PPI regimens (P-CAB: JPY391 vs PPIs: JPY28.6-268.6 per daily prescribed dose). ${ }^{28}$ However, our results, using the real-world data from 2015 to 2018, showed that the total costs of eradication therapy were approximately JPY200 lower per patient in the P-CAB regimen than in the PPI regimen group, despite the approximately JPY 1000 greater per-patient cost of first-line 

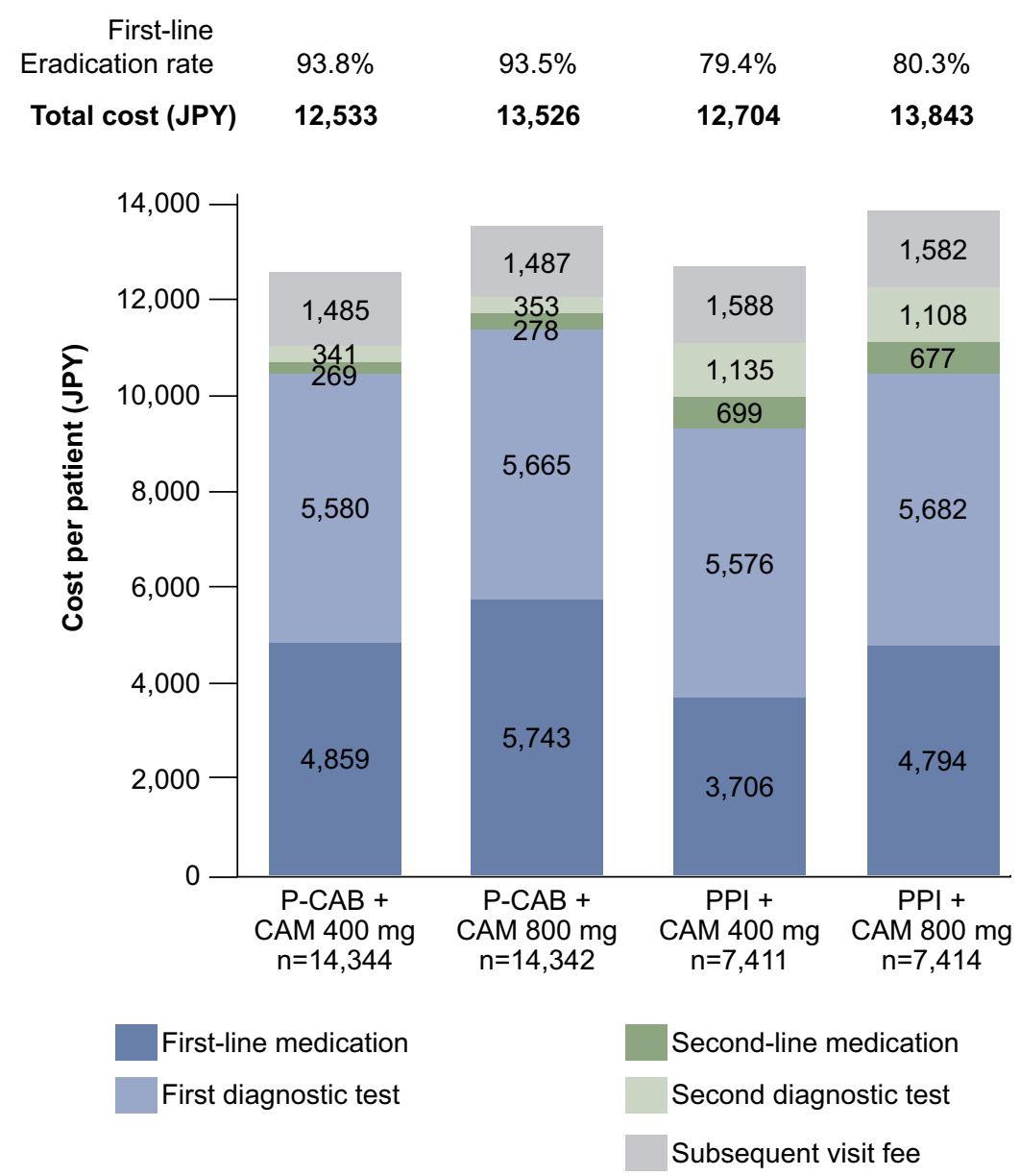

Figure 3 Total costs for Helicobacter pylori eradication therapy between the CAM $400 \mathrm{mg} /$ day and CAM $800 \mathrm{mg} /$ day groups in P-CAB and PPI-based regimens. Total costs are presented as mean values per patient.

Abbreviations: CAM, clarithromycin; JPY, Japanese yen; P-CAB, potassium-competitive acid blocker; PPI, proton pump inhibitor.

medication with P-CAB regimens. Kajihara et $\mathrm{al}^{19}$ reported a hospital-based retrospective study including 209 patients that found that the $\mathrm{P}-\mathrm{CAB}$ regimen was more cost-effective than an RPZ regimen based on first-line eradication rates in the intention-to-treat analysis. Seko et $\mathrm{al}^{20}$ found that there were no significant differences in cost-effectiveness for both first-line and second-line eradications between the P-CAB and LPZ regimens among 442 pharmacist-managed outpatients. Our findings cannot be compared directly with these previous two Japanese cost-analysis studies owing to the different definitions of total costs and evaluations. However, it can be concluded that a triple therapy that achieves high first-line eradication rates can contribute to an overall cost-saving for $H$. pylori eradication therapy by reducing the costs related to second-line eradication therapy.

After exploratively investigating associations between several patient demographic/drug-related factors (eg, age, CAM dose, and product packaging) and eradication rates/ total costs, we focused on the potential differences between higher versus lower doses of CAM. Some previous Japanese studies have reported that the first-line eradication rates did not differ significantly by CAM dose in OPZ-, LPZ-, or VPZ-based triple therapy regimens. ${ }^{15,29,30}$ However, CAM dose-specific cost analysis of eradication therapy was not available for Japan. In our study, the total costs were approximately JPY 1000 per patient lower with CAM $400 \mathrm{mg}$ /day than with CAM $800 \mathrm{mg} /$ day regardless of type of acid inhibitor, while the first-line eradication rates were similar between the two CAM dose regimens. Moreover, analyses limited to the regimens with CAM $400 \mathrm{mg}$ /day showed that total costs were consistently lower in the P-CAB regimen than in the PPI regimen group due to the significant higher success rates of first-line eradication with the P-CAB regimen. These results suggest that a triple therapy regimen with P-CAB and CAM $400 \mathrm{mg} /$ day could be optimal for 


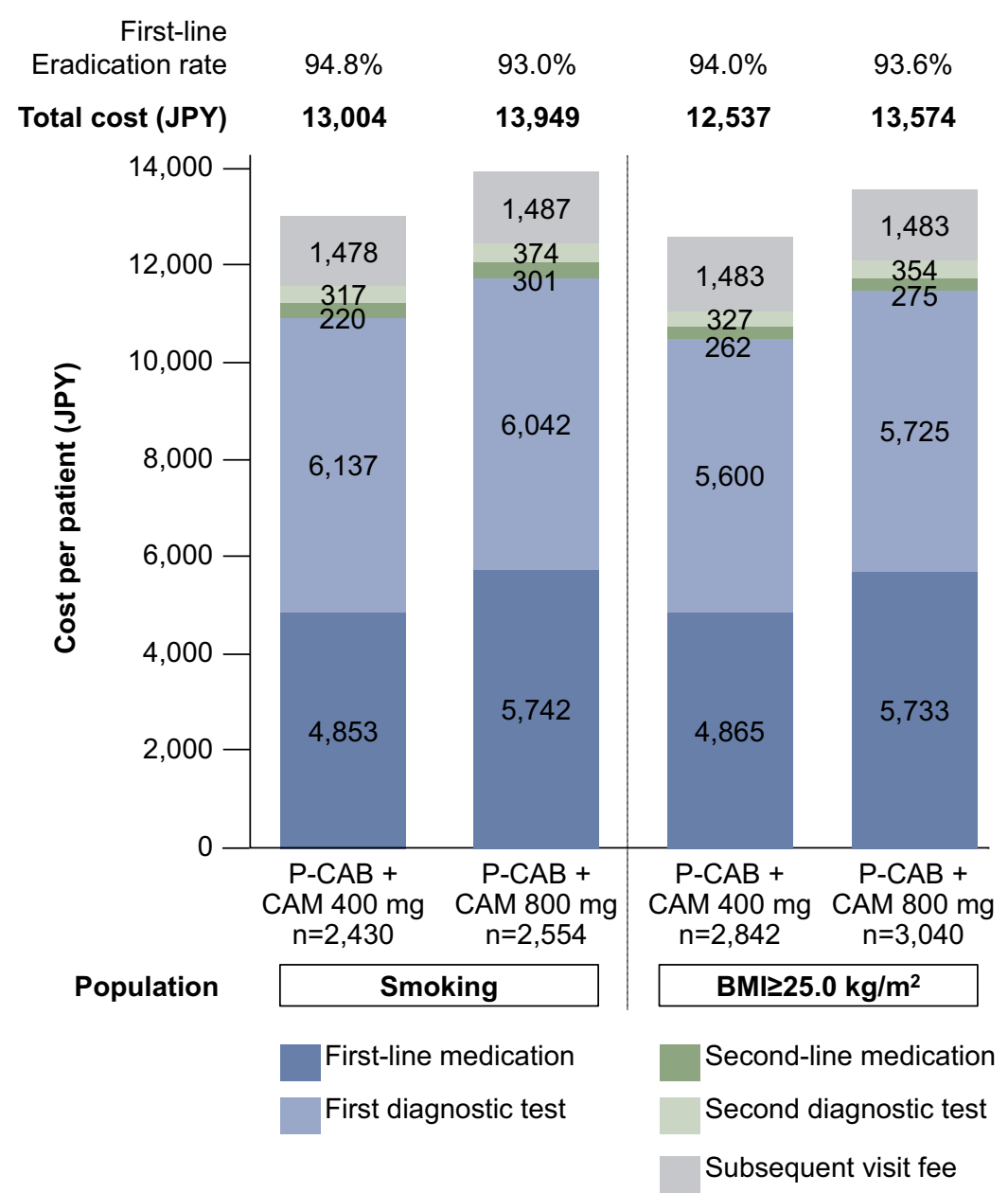

Figure 4 Total costs for Helicobacter pylori eradication therapy per patient between CAM $400 \mathrm{mg} /$ day and CAM $800 \mathrm{mg} / \mathrm{day}$ in P-CAB treated patients with smoking habit or overweight/obese. Total costs are presented as mean values per patient.

Abbreviations: BMI, body mass index; CAM, clarithromycin; JPY, Japanese yen; P-CAB, potassium-competitive acid blocker.

first-line eradication therapy in terms of successful firstline eradication rates and costs saved.

We further evaluated the first-line eradication rates and total costs according to patients' current smoking status and BMI; these factors were chosen because previous studies suggested that there may be a correlation between eradication rates and CAM dose among patients with smoking habit and higher bodyweight. ${ }^{31,32}$ A hospitalbased retrospective study including 601 patients with peptic ulcer diseases showed that among current smokers, the first-line eradication rates with a PPI and CAM $800 \mathrm{mg} /$ day regimen were higher than that with a PPI and CAM $400 \mathrm{mg} /$ day regimen. ${ }^{32}$ It is likely that smoking decreases gastric mucosal blood flow, thus reducing the delivery of antibiotics to the gastric mucosa. ${ }^{32}$ Among current smokers, our real-world data showed that the first-line eradication rates were similar between the CAM $400 \mathrm{mg} /$ day and $800 \mathrm{mg}$ /day groups in both PPI and P-CAB regimens, and this result was inconsistent with the previous hospitalbased study. ${ }^{32}$ The total costs among patients with current smoking were lower with CAM $400 \mathrm{mg} /$ day than with CAM $800 \mathrm{mg} /$ day in both PPI and P-CAB regimens. However, the total costs among current smokers were approximately JPY100 higher in the P-CAB + CAM $400 \mathrm{mg} /$ day regimen than in the PPI + CAM $400 \mathrm{mg} /$ day regimen despite the higher first-line eradication rates with the P-CAB + CAM $400 \mathrm{mg}$ /day regimen than with PPI + CAM $400 \mathrm{mg} /$ day regimen. It might be because the higher diagnostic test cost for first-line eradication therapy was only observed in the P-CAB + CAM $400 \mathrm{mg}$ /day group compared with others. The diagnostic test costs for firstline eradication therapy do not depend on the eradication therapy, whereas the cost associated with second-line diagnosis and eradication therapy may be reduced by a higher first-line eradication rate. Overall, total costs per patient, excluding testing costs for first-line eradication, were 
lower in P-CAB + CAM $400 \mathrm{mg} /$ day (JPY 6907) than in the PPI + CAM $400 \mathrm{mg} /$ day (JPY 7069) group. Therefore, we conclude that P-CAB + CAM $400 \mathrm{mg} /$ day may be an efficient eradication regimen for patients who were current smokers from a cost-saving perspective.

A previous hospital-based study including 81 patients with $H$. pylori positive naïve showed that higher BMI was associated with lower eradication rates. ${ }^{31}$ Moreover, a cohort study that included patients receiving antibiotics for various infections reported that obesity was a risk factor for antibiotic treatment failure because of its effects on the distribution and clearance of drugs. ${ }^{33}$ We found that the first-line eradication rates did not differ by the CAM dose in both $\mathrm{P}-\mathrm{CAB}$ and PPI regimens, and the total costs were lower in P-CAB + CAM $400 \mathrm{mg} /$ day than in the PPI + CAM $400 \mathrm{mg} /$ day group among patients with large body size. Furthermore, post-marketing surveillance data of patients receiving $\mathrm{P}-\mathrm{CAB}$ treatment reported that the CAM $400 \mathrm{mg} /$ day regimen had lower rates of drugrelated adverse events (eg, nausea, nervous system disorders) than the CAM $800 \mathrm{mg} /$ day regimen. ${ }^{34}$ These findings suggest that irrespective of smoking habit or body weight, a triple therapy regimen with P-CAB and CAM $400 \mathrm{mg}$ / day was more likely to reduce the patient burden not only in terms of efficacy and safety but also in terms of costbenefit.

To the best of our knowledge, this is the first study to provide real-world data on cost of $H$. pylori eradication therapy using a large nationwide database of health insurance claims in Japan. However, our study has several limitations. First, our study captures real-world data on healthcare resource consumption for standardized H. pylori eradication therapy in Japan, but it did not include any evaluations for cost-effectiveness. Realworld evidence combined with future cost evaluation modelling can help identify a cost-effective $H$. pylori eradication regimen that will minimize the economic burden not only for patients but also for the public healthcare system. Second, these results may not be directly comparable with previous studies from other countries due to differences in eradication therapy regimen (type of antibiotics, with/without acid-inhibitory medicine and treatment duration). ${ }^{16-18}$ The tripletherapy with P-CAB may be useful among the countries or regions showing high CAM-resistance because P-CAB-based regimens have been associated with higher first-line eradication rates than PPI-based regimens in CAM-resistant H. pylori strains. ${ }^{13,15}$ Further evaluations are needed to assess the cost-effectiveness of a P-CAB-based eradication therapy specific to different regions. Third, the claims data were derived from multiple health insurers for corporate employees and their families. Therefore, it may not be possible to generalize these findings to populations with different backgrounds. Fourth, the success rate of first-line eradication in our study may be overestimated compared with clinical practice because we excluded patients tested later than 6 months after eradication. However, this definition is supported by a real-world report that found the average interval between first-line eradication and diagnostic testing was 8-9 weeks, and that $89.6 \%$ of the patients were tested by urea breath test after both first and second-line eradication therapies. ${ }^{21}$ Also, patients who failed first-line eradication but did not receive second-line eradication therapy during the 6-month follow-up period were counted as patients with successful first-line eradication therapy. Fifth, the design of this study did not incorporate the possible factors in clinical practice that may influence eradication rates (eg, false-negative $H$. pylori infection tests after first-line eradication). Furthermore, data on diagnostic tests to distinguish CAM-resistant or susceptible $H$. pylori strains were unavailable in the insurance claims database used. Finally, the data for subsequent visit fees were not derived from the claims data but were added uniformly across all patients in accordance with visits to medical institutions meeting the study definition of "subsequent visit".

\section{Conclusions}

Our real-world analysis showed that high success rates of first-line $H$. pylori eradication therapy can reduce the need for second-line eradication therapy, thereby saving total eradication costs irrespective of the patient's smoking habit or BMI class. In Japan, a regimen with a more potent acid-inhibitory medicine and low-dose CAM is more likely to reduce the patient burden, not only in terms of efficacy, but also in terms of cost-benefit for the $H$. pylori eradication triple therapy.

\section{Data Sharing Statement}

The data that support the findings of this study are available with permission from JMDC Inc. (https://www.jmdc. co.jp/) under the same conditions as used in this study. Restrictions apply to the availability of these data, which 
were used under a contract between JMDC Inc. and Takeda Pharmaceutical Company Limited.

\section{Acknowledgments}

The authors would like to thank Professor Rei Goto of Keio University for expert advice from a health economics perspective to develop the study design of cost analysis using large claims database (until December 2019). The authors would like to thank Sachie Inoue and Hidetoshi Shibahara of CRECON Medical Assessment Inc. for data management and statistical analyses, and Akihito Uda, Mihoko Ota, and Kazuo Ueda of Takeda Pharmaceutical Company Limited for the study design. Medical writing assistance was provided by Yukiko Homma and Serina Stretton of ProScribe - Envision Pharma Group, Alister Smith, and Magdalene Chu from MIMS (Hong Kong) and was funded by Takeda Pharmaceutical Company Limited.

The results discussed in this manuscript were presented in part at the 25th Annual Meeting of the Japanese Society for Helicobacter Research (2019).

\section{Author Contributions}

All authors made substantial contributions to conception and design, acquisition of data, or analysis and interpretation of data; took part in drafting the article or revising it critically for important intellectual content; agreed to submit to the current journal; gave final approval of the version to be published; and agree to be accountable for all aspects of the work.

\section{Funding}

This study was sponsored by Takeda Pharmaceutical Company Limited, manufacturer/licensee of vonoprazan. The study sponsor was involved in the study design, data collection, data analysis, and preparation of the manuscript.

\section{Disclosure}

KT has no conflicts of interest to declare. CS, MH, and IF are employees of Takeda Pharmaceutical Company Limited. The authors report no other conflicts of interest in this work.

\section{References}

1. Hooi JKY, Lai WY, Ng WK, et al. Global prevalence of Helicobacter pylori infection: systematic review and meta-analysis. Gastroenterology. 2017;153(2):420-429. doi:10.1053/j.gastro.2017.04.022
2. Kodama M, Murakami K, Okimoto T, et al. Ten-year prospective follow-up of histological changes at five points on the gastric mucosa as recommended by the updated Sydney system after Helicobacter pylori eradication. J Gastroenterol. 2012;47(4):394-403. doi:10. 1007/s00535-011-0504-9

3. Kato M, Ota H, Okuda M, et al. Guidelines for the management of Helicobacter pylori infection in Japan: 2016 revised edition. Helicobacter. 2019;24(4):e12597. doi:10.1111/hel.12597

4. Asaka M, Kato M, Graham DY. Strategy for eliminating gastric cancer in Japan. Helicobacter. 2010;15(6):486-490. doi:10.1111/ j.1523-5378.2010.00799.x

5. de Martel C, Forman D, Plummer M. Gastric cancer: epidemiology and risk factors. Gastroenterol Clin North Am. 2013;42(2):219-240. doi:10.1016/j.gtc.2013.01.003

6. Fukase K, Kato M, Kikuchi S, et al. Effect of eradication of Helicobacter pylori on incidence of metachronous gastric carcinoma after endoscopic resection of early gastric cancer: an open-label, randomised controlled trial. Lancet. 2008;372(9636):392-397. doi:10.1016/S0140-6736(08)61159-9

7. Tsuda M, Asaka M, Kato M, et al. Effect on Helicobacter pylori eradication therapy against gastric cancer in Japan. Helicobacter. 2017;22(5):e12415. doi:10.1111/hel.12415

8. National Cancer Center. National cancer center, latest cancer statistics - Japan 2018 [Japanese]. Available from: https://ganjoho.jp/reg stat/statistics/stat/summary.html. Accessed April 2, 2021.

9. Graham DY, Fischbach L. Helicobacter pylori treatment in the era of increasing antibiotic resistance. Gut. 2010;59(8):1143-1153. doi:10. 1136/gut.2009.192757

10. Hashinaga M, Okimoto T, Kodama M. 我が国における薬剂耐性 Helicobacter pylori の現状 [Drug resistance in Japan: the present status of Helicobacter pylori; the overall results of the resistant strain survey in 2013 and 2014]. Jpn J Helicobacter Res. 2016;17(2):45-49. Japanese.

11. Kawai T, Takahashi S, Suzuki H, et al. Changes in the first line Helicobacter pylori eradication rates using the triple therapy a multicenter study in the Tokyo metropolitan area (Tokyo Helicobacter pylori study group). J Gastroenterol Hepatol. 2014;29 (Suppl 4):29-32. doi:10.1111/jgh.12796

12. Hori Y, Matsukawa J, Takeuchi T, Nishida H, Kajino M, Inatomi N. A study comparing the antisecretory effect of TAK-438, a novel potassium-competitive acid blocker, with lansoprazole in animals. J Pharmacol Exp Ther. 2011;337(3):797-804. doi:10.1124/jpet.11 1.179556

13. Li M, Oshima $\mathrm{T}$, Horikawa $\mathrm{T}$, et al. Systematic review with meta-analysis: vonoprazan, a potent acid blocker, is superior to proton-pump inhibitors for eradication of clarithromycin-resistant strains of Helicobacter pylori. Helicobacter. 2018;23(4):e12495. doi:10.1111/hel.12495

14. Lyu Q-J, Pu Q-H, Zhong X-F, Zhang J. Efficacy and safety of vonoprazan-based versus proton pump inhibitor-based triple therapy for Helicobacter pylori eradication: a meta-analysis of randomized clinical trials. Biomed Res Int. 2019;2019:9781212. doi:10.1155/2019/9781212

15. Murakami K, Sakurai Y, Shiino M, Funao N, Nishimura A, Asaka M. Vonoprazan, a novel potassium-competitive acid blocker, as a component of first-line and second-line triple therapy for Helicobacter pylori eradication: a Phase III, randomised, double-blind study. Gut. 2016;65(9):1439-1446. doi:10.1136/gutjnl2015-311304

16. Farhoud NS, Ibrahim OM, Ezzat SE. Efficacy and cost-effectiveness comparison of 10-day, 14-day sequential versus 14-day triple therapies for treating Helicobacter pylori infection in Egyptian patients. J Clin Gastroenterol. 2020;54(9):806-812. doi:10.1097/MCG.000 0000000001278

17. Papaefthymiou A, Liatsos C, Georgopoulos SD, et al. Helicobacter pylori eradication regimens in an antibiotic high-resistance European area: a cost-effectiveness analysis. Helicobacter. 2020;25(1):e12666. doi:10.1111/hel.12666 
18. Yi D-M, Yang -T-T, Chao S-H, et al. Comparison the cost-efficacy of furazolidone-based versus clarithromycin-based quadruple therapy in initial treatment of Helicobacter pylori infection in a variable clarithromycin drug-resistant region, a single-center, prospective, randomized, open-label study. Medicine (Baltimore). 2019;98(6):e14408. doi:10.1097/MD.0000000000014408

19. Kajihara Y, Shimoyama T, Mizuki I. Analysis of the cost-effectiveness of using vonoprazan-amoxicillin-clarithromycin triple therapy for first-line Helicobacter pylori eradication. Scand J Gastroenterol. 2017;52(2):238-241. doi:10.1080/00365521.2016.1250157

20. Seko T, Tachi T, Hatakeyama H, Noguchi Y, Teramachi H. Costeffectiveness analysis and effectiveness of pharmacist-managed outpatient clinics in Helicobacter pylori eradication therapy. Int J Clin Pract. 2019;73(6):e13349. doi:10.1111/ijcp.13349

21. Deguchi H, Uda A, Murakami K. Current status of Helicobacter pylori diagnosis and eradication therapy in Japan using a nationwide database. Digestion. 2020;101(4):441-449. doi:10.1159/000500819

22. Deguchi H, Yamazaki H, Yamamoto Y, Fukuhara S. Association between parental history of Helicobacter pylori treatment failure and treatment failure in the offspring. $J$ Gastroenterol Hepatol. 2019;34(12):2112-2117. doi:10.1111/jgh.14774

23. Mori H, Suzuki H, Omata F, et al. Current status of first- and second-line Helicobacter pylori eradication therapy in the metropolitan area: a multicenter study with a large number of patients. Therap Adv Gastroenterol. 2019;12:1756284819858511. doi:10.1177/1756 284819858511

24. Hirayama Y, Kawai T, Otaki J, Kawakami K, Harada Y. Prevalence of Helicobacter pylori infection with healthy subjects in Japan. J Gastroenterol Hepatol. 2014;29(Suppl 4):16-19. doi:10.1111/jgh.12795

25. Hiroi S, Sugano K, Tanaka S, Kawakami K. Impact of health insurance coverage for Helicobacter pylori gastritis on the trends in eradication therapy in Japan: retrospective observational study and simulation study based on real-world data. BMJ Open. 2017;7(7): e015855. doi:10.1136/bmjopen-2017-015855

26. Sugano K, Hiroi S, Yamaoka Y. Prevalence of Helicobacter pylori infection in Asia: remembrance of things past? Gastroenterology. 2018;154(1):257-258. doi:10.1053/j.gastro.2017.08.074
27. Ozaki H, Harada S, Takeuchi T, et al. Vonoprazan, a novel potassium-competitive acid blocker, should be used for the Helicobacter pylori eradication therapy as first choice: a large sample study of vonoprazan in real world compared with our randomized control trial using second-generation proton pump inhibitors for Helicobacter pylori eradication therapy. Digestion. 2018;97 (3):212-218. doi:10.1159/000485097

28. Meteo. Medical*online [Japanese]. Available from: http://pha.medica lonline.jp. Accessed April 2, 2021.

29. Higuchi K, Maekawa T, Nakagawa K, et al. Efficacy and safety of Helicobacter pylori eradication therapy with omeprazole, amoxicillin and high- and low-dose clarithromycin in Japanese patients: a randomised, double-blind, multicentre study. Clin Drug Investig. 2006;26(7):403-414. doi:10.2165/00044011-200626070-00002

30. Miwa H, Murai T, Sato K, et al. Comparison of the efficacy of $400 \mathrm{mg}$ and $800 \mathrm{mg}$ of clarithromycin used with lansoprazole and amoxicillin in eradication regimens for Helicobacter pylori infection in a Japanese population. J Gastroenterol. 2000;35(7):536-539. doi:10. $1007 / \mathrm{s} 005350070077$

31. Abdullahi M, Annibale B, Capoccia D, et al. The eradication of Helicobacter pylori is affected by body mass index (BMI). Obes Surg. 2008;18(11):1450-1454. doi:10.1007/s11695-008-9477-z

32. Ishioka H, Mizuno M, Take S, et al. A better cure rate with $800 \mathrm{mg}$ than with $400 \mathrm{mg}$ clarithromycin regimens in one-week triple therapy for Helicobacter pylori infection in cigarette-smoking peptic ulcer patients. Digestion. 2007;75(2-3):63-68. doi:10.1159/000102301

33. Longo C, Bartlett G, Macgibbon B, et al. The effect of obesity on antibiotic treatment failure: a historical cohort study. Pharmacoepidemiol Drug Saf. 2013;22(9):970-976. doi:10.1002/ pds.3461

34. Ashida K, Honda Y, Sanada K, Takemura Y, Sakamoto S. The safety and effectiveness of vonoprazan-based Helicobacter pylori eradication therapy; a prospective post-marketing surveillance. Expert Opin Drug Saf. 2019;18(12):1255-1261. doi:10.1080/ 14740338.2019.1676722
ClinicoEconomics and Outcomes Research

\section{Publish your work in this journal}

ClinicoEconomics and Outcomes Research is an international, peerreviewed open-access journal focusing on Health Technology Assessment, Pharmacoeconomics and Outcomes Research in the areas of diagnosis, medical devices, and clinical, surgical and pharmacological intervention. The economic impact of health policy and health systems organization also constitute important areas of coverage. The manuscript management system is completely online and includes a very quick and fair peer-review system, which is all easy to use. Visit http://www.dovepress.com/testimonials.php to read real quotes from published authors.

Submit your manuscript here: https://www.dovepress.com/clinicoeconomics-and-outcomes-research-journal 